\title{
Un modelo a imitar: Disney en Ezeiza y el proyecto empresarial de Dante Quinterno ${ }^{1}$
}

\author{
A role model: Disney in Ezeiza and the business plan of Dante \\ Quinterno
}

Laura Vazquez $^{2}$

\begin{abstract}
This article belongs to the transnational cultural studies field and seeks to contrast the film "Saludos Amigos" of the Disney Studios and the short film "Upa en apuros" made in the Dante Quinterno's studios, both created in the year 1941/1942. As we shall see, while the films produced by Disney are a "work made for hire" Quinterno production accounts for the interest of the editor to follow the footsteps of his teacher, but above all, it shows Quinterno's will to progress. The way in which one of the most conservative and traditional employers carries on this plan has its own contradictions. I will start from a set of problems arising from the few sources available on Walt Disney's visit to Argentina, with the ultimate goal of avoiding the reductionism that suggests a linear phenomenon of 'Americanization' of entertainment supply in our country.
\end{abstract}

Keywords: Comic. Cultural diplomacy. Disney. Dante Quinterno. Market. Progress.

RESUMEN

Este artículo se inscribe en la línea de los estudios culturales transnacionales y busca contrastar el filme Saludos Amigos de los Estudios Disney y el cortometraje Upa en Apuros de la Empresa Dante Quinterno, ambos creados en el año 1941/1942. Como veremos, mientras que los filmes producidos por Disney resultan de un "trabajo por encargo" la producción de Quinterno da cuenta del interés del editor por seguir los pasos de su maestro, pero sobre todo, de su ambición por posicionarse de cara al progreso. El modo en el uno de los más conservadores y tradicionales empresarios del rubro encara este plan no está exento de contradicciones. Para ello partiré de un conjunto de problemas surgidos de las escasas fuentes disponibles sobre la visita de Walt Disney a la Argentina con el objetivo final de evitar el reduccionismo que lleva a pensar en un fenómeno lineal de "americanización" de la oferta de entretenimientos.

\footnotetext{
${ }^{1}$ Este artículo forma parte de mi investigación actual en CONICET: "Un proyecto de industria cultural nacional: análisis comparativo del mercado de producción de historietas en la Argentina entre 1942 y 1968 ".

${ }^{2}$ Docente en la cátedra "Historia de los Medios", Carrera de Ciencias de la Comunicación, Universidad de Buenos Aires (UBA). Investigadora del Consejo Nacional de Ciencia y Técnica (CONICET). Instituto Gino Germani, UBA.
} 


\section{¿David contra Goliat?}

No es novedad poner en evidencia los efectos de la diplomacia cultural ni dar cuenta de uno de sus canales regulares: la cultura de masas. El grado de imbricación entre el Departamento de Estado y Hollywood durante la segunda guerra ya ha sido puesto de manifiesto en una profusa bibliografía. Claramente, no forma parte este trabajo volver sobre esos pasos. Por el contrario, me interesa partir de los vínculos entre distintos actores ligados al gobierno y al mercado para dar pensar hasta qué punto los efectos de una política exterior como las misiones de "buena vecindad" repercutieron en el escenario nacional.

En tal sentido, este ensayo pone comillas a la concepción de la industria de la historieta como una "herramienta cultural" y acentúa las estrategias de resignificación, posiciones previas y relativa autonomía antes que los efectos propagandísticos de una campaña ideológica. En otros términos: la adopción de métodos de trabajo, producción y estandarización creativa impactó en el campo de la historieta de un modo que difícilmente podría encuadrarse en los objetivos inmediatos de una política más amplia.

La posición de Dante Quinterno oscila entre una defensa radical de los valores nacionales y la intención de colocar productos que puedan competir en el mercado. En tanto "empresario de la cultura" diversificó su oferta en el marco de un proceso de homogeneización de públicos y expansión territorial. Comprender la lógica de esta tendencia convergente y simultánea implica dejar de leer al Pato Donald desde la perspectiva del colonialismo y a Disney como una factoría de ideología dominante, para pensar en los procesos de desterritorialización (ORTIZ, 1994) y negociación de identidades (GARCÍA CANCLINI, 1995) de la cultura de masa.

En Saludos Amigos Disney es presentado como un embajador de culturas (que recuerda los viajes transoceánicos de principios del siglo XX) y como un visionario que advierte en tierras sudamericanas un proyecto hacia el futuro. Es imposible dejar de notar la ideología de sus realizadores, pero lo interesante, en este caso, es tensar los hilos de una comparación, en principio, imposible. Quiero decir, si Dante Quinterno en el imaginario argentino es el "Disney latinoamericano" ello sólo tendría sentido en el marco del fracaso de su proyecto.

A partir del axioma: "Quinterno no es Disney" cabe preguntarse por los rasgos diferenciales de su empresa, sus estrategias de imitación de un modelo importado, el modo en el 
que mixturó y se reapropió de un ideal hegemónico, o mejor aún, si no contribuyó con su propia iniciativa a consolidar y construir a esa visión de mundo. Entiendo que Quinterno es algo más que la versión empobrecida de una discursividad dominante y me niego a pensar que Disneylandia tuvo tal efecto multiplicador que subvirtió otras ideologías en pugna. Sin hacer futurología, creo que el derrotero no hubiese muy distinto si Disney no visitaba la Argentina.

Entonces, lo que me interesa es invertir la carga de la prueba y en vez de partir de Disney para mostrar cómo su política empresarial influyó en la producción de Quinterno, analizar la complejidad del proceso y atender los modos diferenciales de la "apropiación". ${ }^{3}$ La intención es bucear en los vínculos existentes en el mercado de entretenimiento en un período signado por la transformación de la industria cultural y me propongo hacerlo, además, atendiendo la influencia reciproca siguiendo la idea de magnetismo cultural planteada por Peter Burke. ${ }^{4}$

Por otra parte, entiendo que existe una contigüidad entre el sector editorial de historietas y la industria del cine. A su vez, ello desencadenará convergencias con otros sectores de la producción dando lugar a procesos contradictorios y complementarios de homogeneización industrial. No podré trabajar este tema aquí pero este artículo no podría desprenderse de esos objetivos: la industria de la historieta argentina no está escindida de los complejos transnacionales de producción y de las formas hegemónicas de acción de la globalización en los medios y la industria cultural. (VAZQUEZ, 2010).

\section{Saludos amigos y buenos vecinos}

A principios de los años cuarenta Walt Disney visitó el continente latinoamericano con la misión de consolidar y expandir la política de "buena vecindad" iniciada por el gobierno de Estados Unidos en 1939. El objetivo central de esta misión consistió en el esfuerzo de desarrollar estrategias destinadas a estrechar los lazos culturales, políticos y comerciales de Norteamérica con América Latina, mantener el liderazgo del país en el continente, impedir la influencia europea y frenar un posible avance del comunismo. Es en este marco que cabe analizar el paso de la Comitiva de Disney por América Latina en tanto "artefacto cultural" cuya instrumentalización sería coordinada por el Departamento de Estado de EEUU.

\footnotetext{
${ }^{3}$ Los aportes que contribuyen a estas reflexiones los he tomado, fundamentalmente de Peter Burke (2000) y Michael de Certeau (1999)

${ }^{4}$ El historiador denomina magnetismo cultural a la atracción entre elementos similares de dos sociedades diferentes (BURKE, 2000, p. 203).
} 
El estudio Disney atravesaba problemas financieros y por una de las más potentes huelgas de la historia sindical en Hollywood, ${ }^{5}$ en este sentido, la propuesta del gobierno, resultaba una tentación para la compañía y una oferta por demás conveniente. No fue la primera vez que el dibujante trabajaba para la "causa norteamericana"; entre 1941 y 1942 realiza una serie de animaciones entre las que se destacan: Victory Through Air Force, los cortos Private Pluto, Commando Duck y Victory Vehicles. Estos filmes fueron producidos con el apoyo de entidades gubernamentales de Estados Unidos y Canadá, desde antes de diciembre de 1941, fecha en que EEUU entró directamente a la guerra.

Entre 1941 y 1946 la compañía realizó 28 "filmes educaciones" y 80 destinados al entrenamiento militar, además de 6 grandes producciones para la industria cinematográfica. A ello hay que agregar la voluminosa suma de 70 cortometrajes, de los cuales 6 fueron nominados al Oscar y dos lo obtuvieron: Der Fuhrés Face y Lend a Paw. (PURCELL, 2010, p. 510) ${ }^{6}$ Hay que señalar que gran parte del material producido con fines específicos está fuera de circulación y en la actualidad es prácticamente inhallable.

Quizá la más conocida de estas animaciones sea Der Fuhrés Face, en donde Donald sueña que está en la Alemania nazi, trabaja en una fábrica de municiones y es forzado a saludar a Hitler de manera compulsiva. Al despertar de su pesadilla, advierte una sombra con el brazo levantado y grita "Heil" pero enseguida se da cuenta que la imagen proviene de un adorno: una Estatua de la Libertad que tiene en su ventana. Salta feliz de su cama y en pijama rojo, azul y blanco, besa el objeto y canta: “iOh, Boy estoy orgulloso de ser ciudadano de los Estados Unidos de América!” Al finalizar la cinta, un Hitler caricaturizado recibe un tomatazo en la cara al mejor estilo del stand up comedy.

Figura 1 - Afiche del filme Der Fuhrés Face

\footnotetext{
${ }^{5}$ En 1938 es creada el Screen Cartoonits Guild, primer sindicato de la industria de la animación. El mismo desarrolló una campaña intensa para sumar afiliados entre los trabajadores del medio. Disney prohibió la afiliación sindical de sus empleados entre quienes crecía el reclamo por el pago de las bonificaciones de las horas extra y reconocimiento de créditos y beneficios. . Disney despidió a un grupo de trabajadores y animadores, el 28 de mayo de 1941 se desató una fuerte huelga en los estudios de su industria. Finalmente, y gracias a la mediación del gobierno federal y de varios grupos de presión (entre ellos, su principal acreedor, el Bank of America) Disney aceptó reconocer al sindicato y mejorar parcialmente las condiciones de contratación. La huelga concluyó tras nueve semanas.

${ }^{6}$ Se recomienda el trabajo de Fernando Purcell en donde se analiza cuidadosamente el impacto de los filmes de propaganda en Chile durante los años de la guerra fría. Purcell, 2010. Su análisis sobre Walt Disney en Chile ha sido particularmente iluminador para la escritura de este artículo.
} 


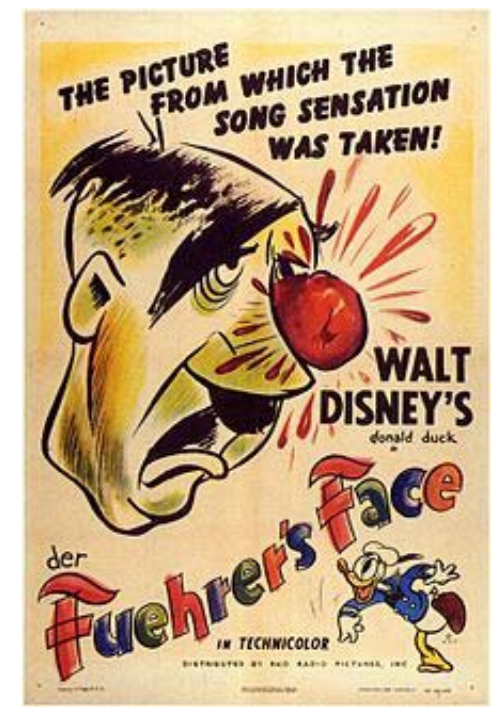

Fonte: Archivo personal de la autora.

El proyecto que dio origen a Saludos Amigos (1943) y Los tres Caballeros (1945) se comenzó a discutir en 1941. En su origen, planteaba la producción de 12 cortometrajes en donde aparezcan las creaciones de Disney junto a nuevos personajes sudamericanos. La aprobación vino por intermedio de una carta enviada a John C. McClintock, "bajo el entendido de que la película, cuando se haya completado, debe ser revisada por representantes del Departamento de Estado para su aprobación final". (PURCELL, 2010) El proyecto fue definido así:

Mientras el viaje de Disney constituyó un gesto sustancial de buena voluntad, una película basada en el viaje será el mayor gesto de adulación para el resto de las repúblicas americanas y pondrá énfasis en los lazos comunes que unen a la gente de las Américas. En un momento en que la solidaridad continental es de primerisima importancia, esta película proporcionará una demostración persuasiva de nuestros buenos deseos vistos en acción. Este tipo de factores unificadores, como los de esta película, son esenciales para la moral de los civiles tanto en nuestro país como en el resto de las Américas. ${ }^{7}$

El viaje de la comitiva fue preparado y diseñado por Nelson Rockefeller, en ese entonces Secretario de Asuntos Internacionales del presidente Franklin Delano Roosevelt. La Office of the

\footnotetext{
7 "Walt Disney Sees South America", Proyect Authorization, 18 de diciembre de 1941, NARA, RG 229, Caja 216, Carpeta, "Walt Disney Sees South America", citado en Purcell, (2010, p. 513).
} 
Cordinator of Inter-American (OCCIA) dirigida por Rockefeller buscaba fortalecer una visión positiva de los Estados Unidos. Con la colaboración directa de las industrias cinematográficas de Hollywood, esta institución promovía el poderío militar de los Estados Unidos al mismo tiempo que buscaba promocionar el American Way of Life a través de su campaña de ofensiva ideológica.

La gira estuvo comprendida por Disney, su esposa y un equipo de dieciséis guionistas, animadores, técnicos y dibujantes entre quienes se encontraba el encargado de negocios John C. Rose y el director musical Charles Wolcott. El viaje se prolongó durante diez semanas: se inició el 6 de agosto de 1941 y concluyó el 22 de octubre con el regreso de los últimos profesionales de los estudios Disney a EEUU.

Figura 2 - Llegada de la Comitiva Disney: expectativa y aventura.

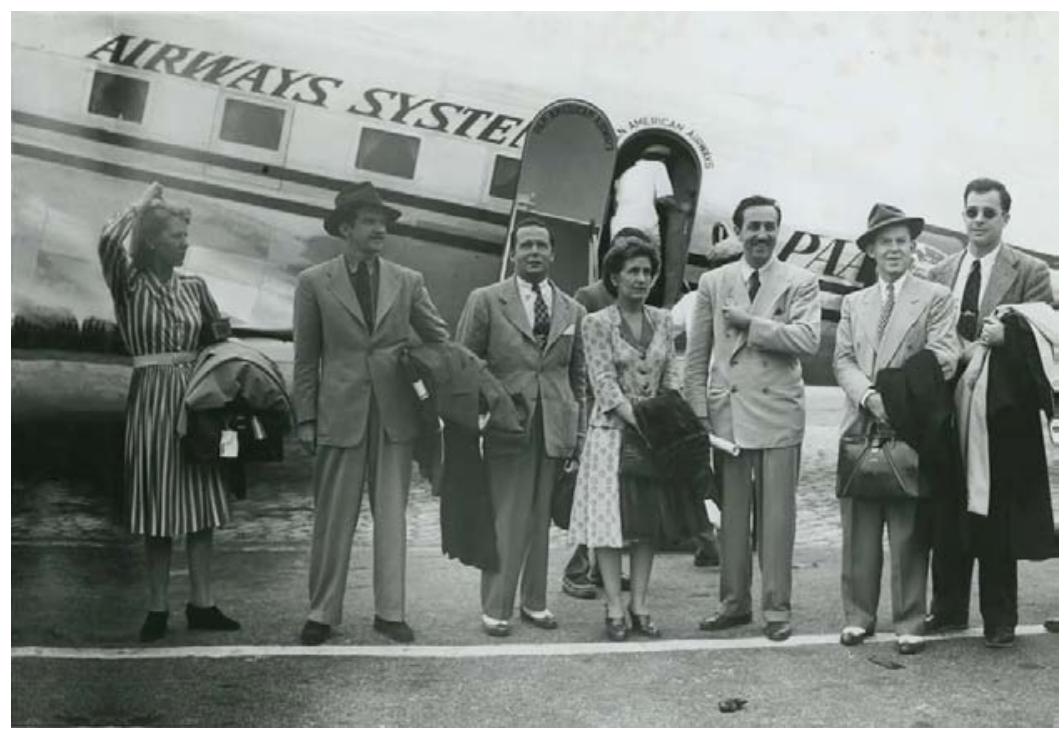

Fonte: Purcell (2010)

La comitiva recorrió los siguientes países: Argentina, Brasil, Uruguay, Chile, Bolivia, Ecuador, Colombia, Panamá, Perú, Guatemala y México. El tiempo de estadía no fue semejante en cada caso siendo posible advertir que ello se debía a los intereses directos de la política norteamericana. Los artistas tomaron fotografías, dibujaron "al natural", filmaron y compartieron experiencias con colegas locales. El material reunido da cuenta del interés de Disney por registrar esa experiencia "antropológica" y construir una imagen que perdurase en el tiempo. $^{8}$

\footnotetext{
${ }^{8}$ El documental Walt y el Grupo (2008), dirigido por Theodore Thomas, hijo de Frank Thomas, uno de los colaboradores más estrechos de Disney e integrante de la comitiva del año 41) fue producido por The Walt Disney Family Foundation y
} 
Figura 3 - Mary Blair y Lee Blair haciendo bocetos

Figura 4 - Walt Disney en las playas de Copacabana

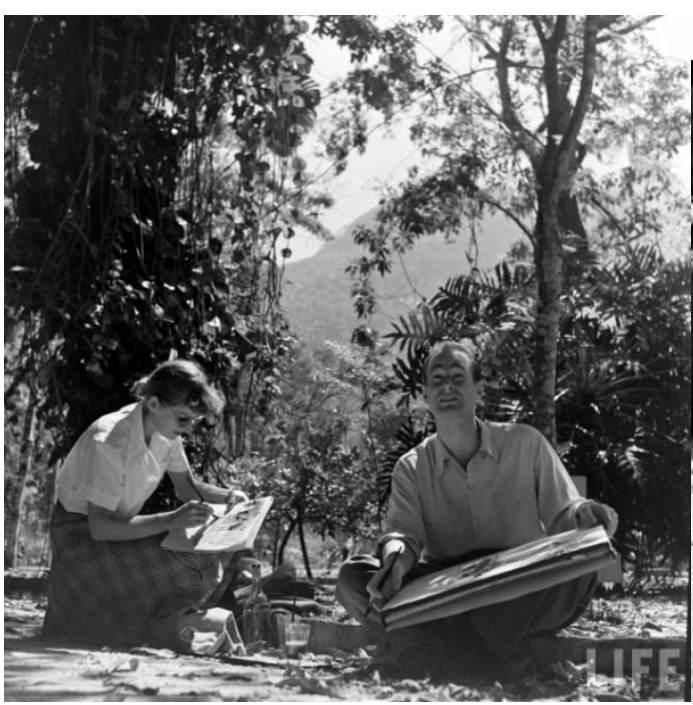

Fonte: Walt Disney no Brasil (2008).

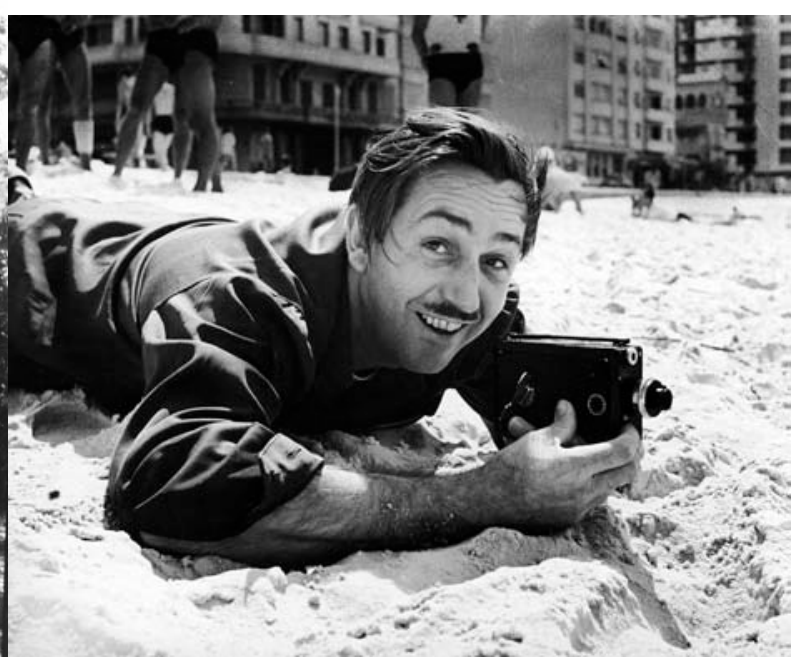

Fonte: Walt Disney no Brasil (2008).

En rigor, Saludos Amigos es la reunión de cuatro cortometrajes que describen el paso de la compañía por América Latina desde agosto a octubre de 1941. El filme fue rodado en los Estudios Disney en febrero de 1943 y tiene una duración de 42 minutos. El documental animado se posiciona a modo de un fresco regional, una aventura por el Lago Titicaca que ilustraba el paso del Pato Donald por Perú, Aquarela do Brasil con José Carioca y Donald bailando en las playas de Copacabana, las aventuras de Pedro el avioncito en la cordillera chilena y El gaucho Goofy en las pampas argentinas.

Figura 5 - Afiche Saludos Amigos.

se estrenó en el año 2008. Su director entrevistó a familiares, dibujantes, periodistas y personalidades con las que Disney tuvo contacto. A partir de la ampliación de fotografías tomadas durante el viaje, investigó los cuadernos de viaje y visitó los sitios originales. 


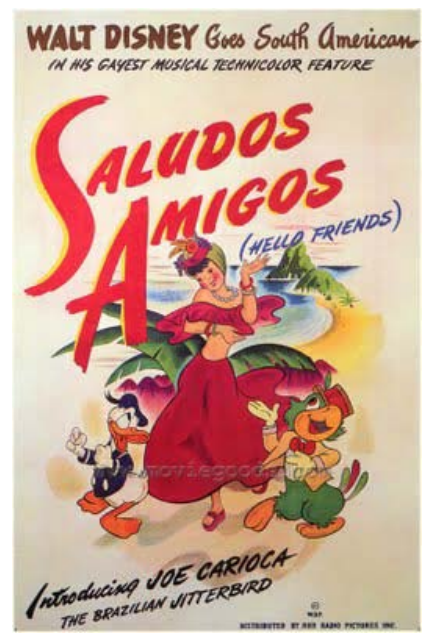

Fonte: Archivo personal de la autora.

El filme comienza con una escena desde el avión que muestra a los expectantes exploradores en tanto una voz en off presenta "la expedición inusual: artistas, músicos y escritores partiendo en busca de nuevos personajes, música y danzas para sus dibujos animados". La intención se revela en las primeras secuencias y en los versos de la banda sonora compuesta por Edward Plumb y entonada durante los créditos iniciales. La música funciona como síntesis del guión y representa el objetivo de la política de buena vecindad: "Saludamos a toda América del Sur/Donde el cielo es siempre azul/Saludamos a todos los amigos del corazón/Que allí dejamos, de quienes nos acordamos al cantar esta canción".

Dos años más tarde, se llevo a cabo la producción del filme Los tres caballeros con material seleccionado durante la misión. ${ }^{9}$ El nuevo filme podría pensarse como una secuela ya que el objetivo no distaba del anterior: mostrar la hermandad de los pueblos americanos a partir de la fusión del registro documental y la animación. En esta ocasión, se presentan personajes como representantes de sus países: El Pato Donald (EEUU), José Carioca (Brasil) Panchito (México) y el Gauchito Volador a (Argentina).

Un mapa estilizado destaca la flora y fauna de la región, prestando atención a la cordillera de los Andes y a la jungla amazónica. Carmen Miranda funciona como símbolo panamericanista y embajadora cultural del "mundo adulto": si el Pato Donald apelaba a los niños, la célebre estrella del espectáculo resultaba una tentación evidente para sus fanáticos seguidores. Cabe señalar que la proyección de Los tres caballeros quedó relegada en la Argentina debido a la

${ }^{9}$ El filme tuvo su estreno mundial en México el 21 de diciembre de 1944. Un año más tarde se presentaría en los Estados Unidos. 
neutralidad declarada del gobierno durante la segunda guerra, incluso después del ingreso de los Estados Unidos al conflicto.

Figura 6 - Afiche Los tres caballeros.

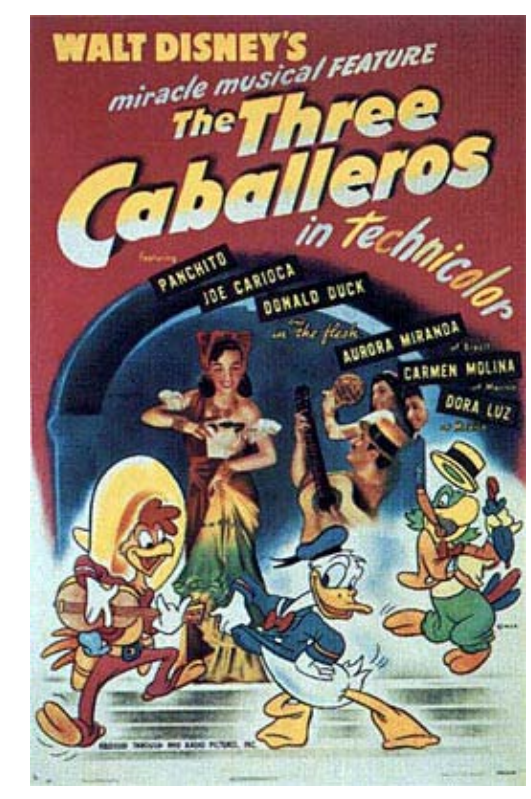

Fonte: Archivo personal de la autora.

En el transcurso de la década del 40 la ofensiva de persuasión ideológica promovida por el gobierno de Roosevelt ocasionó importantes tensiones. El dato no es menor si nos preguntamos hasta qué punto fue efectiva la misión en el país y cuánto de mítico hay en el imaginario que reconstruye a Quinterno como a un "Disney Latinoamericano". Las formas de hibridación cultural están presentes en la resignificación de los elementos hegemónicos. La idea que aquí defiendo no implica olvidar las condiciones desiguales de esa producción ni los modos diferenciales en los que tales procesos operan.

Sin embargo y partiendo de esos datos insoslayables, la adopción del modelo norteamericano y la implantación de un tipo de industria afín a esos intereses desbordó la esfera de la simple adaptación. En las expectativas empresariales de Dante Quinterno (pero también de Ramón Columba y otros editores y dibujantes de la etapa) no sólo hay diferencias con respecto al "patrón original" sino un complejo entramado de negociación que no necesariamente se produce "fronteras afuera". 
En los años de oro del medio, exportar historietas o cereales asumía un carácter programático y especulativo. La promoción de dibujantes, estilos y narrativas "propias" formaba parte de la reorientación de la economía hacia el mercado interno. Así, por esos años, se hacía referencia a "una escuela de la historieta argentina" y a un modo de producción excepcional. (Vazquez, 2010) Ramón Columba, presidente y fundador de la Asociación Argentina de Editores de Revistas de Historietas, señalaba en una entrevista:

¡Nuestras revistas de historietas editan ciento cincuenta millones de ejemplares por año! No hay país del mundo que nos supere en este renglón. De ahí la importancia para los dibujantes argentinos de todo lo que se relaciona con esta actividad que se ha convertido en otra producción característica del país. [...] .Vale decir que los aficionados pueden entregarse a practicar dibujo con la confianza de que no va a faltar trabajo y buena remuneración para ellos. Los buenos, actualmente no da abasto, aun cuando ya son muchos. [...] Cuando estuvo Walt Disney en Buenos Aires, hace dos años, quedó sorprendido cuando le presenté a casi trescientos dibujantes argentinos. "No sospechaba encontrar un foco tan grande y dudo que lo supere Nueva York" -me dijo.- ¿Cuántos artistas colaboran en la Editorial Columba?-Alrededor de cuarenta. Algunos, como Eugenio Colonesse, (3) que aunque es un chico italiano puedo decir que es "producto exclusivo de nuestra editorial".10

Esta perspectiva debe ser leída en el contexto de la política industrial del peronismo y en el afianzamiento de un mercado de historietas competitivo. Al promediar la década del cincuenta, ese rumbo promisorio iniciará su curva descendente pero, hasta entonces, las expectativas configuraban una empresa ambiciosa en donde la admiración y respeto, tenían como su contracara, una carrera competitiva y desafiante.

A continuación abordaré del filme Hola Amigos el episodio Goofy en las Pampas. Es notorio cómo el documental se destaca a la Argentina y a Brasil por sobre el resto de los países americanos visitados durante la gira. Entiendo que la estadía prolongada de Walt y su equipo en Río de Janeiro y Buenos Aires no es un hecho fortuito. La elección de esos países como centros políticos latinoamericanos da cuenta que eran blancos prioritarios de la política externa y que había que ponerle coto a cualquier aspiración de liderazgo regional.

\footnotetext{
${ }^{10}$ Entrevista realizada a Ramón Columba (1891-1959) publicada en el No 4 (Diciembre-Enero 1954) de Dibujantes.
} 


\section{Disney en Ezeiza}

Desde Río de Janeiro, la gira partió hacia Buenos Aires el 8 de septiembre siendo recibidos por una multitud entusiasta en el aeropuerto de Ezeiza. La comitiva permaneció tres semanas en la capital y estableció una suerte de "estudio creativo" en el Alvear Palace Hotel; también visitaron las provincias de Salta y Mendoza. Entre las actividades culturales y encuentros con colegas y artistas se destaca la visita hasta el estudio del pintor Florencio Molina Campos, famoso por sus cuadros gauchescos para los calendarios de la empresa Alpargatas.

Del trabajo conjunto surgieron dos cortos El Gaucho Goofy (en inglés en el original) y $E l$ gauchito volador (The Flying Gauchito), ambos de temática campera. El Gaucho Goofy fue dirigido por Jack Kinney y se estrenó en Buenos Aires en octubre de 1942. En la representación de Argentina, Disney recurre a un tema apreciado por el imaginario norteamericano: la asociación entre el oeste y la frontera. Goofy es un vaquero de la llanura pampeana y su paso por el campo es sólo una circunstancia. En rigor, no necesita aprender a montar su caballo, hacer un asado o dominar un ñandú con las boleadoras porque al fin de cuentas, va a regresar.

Figura 7 - Tradición e identidad.

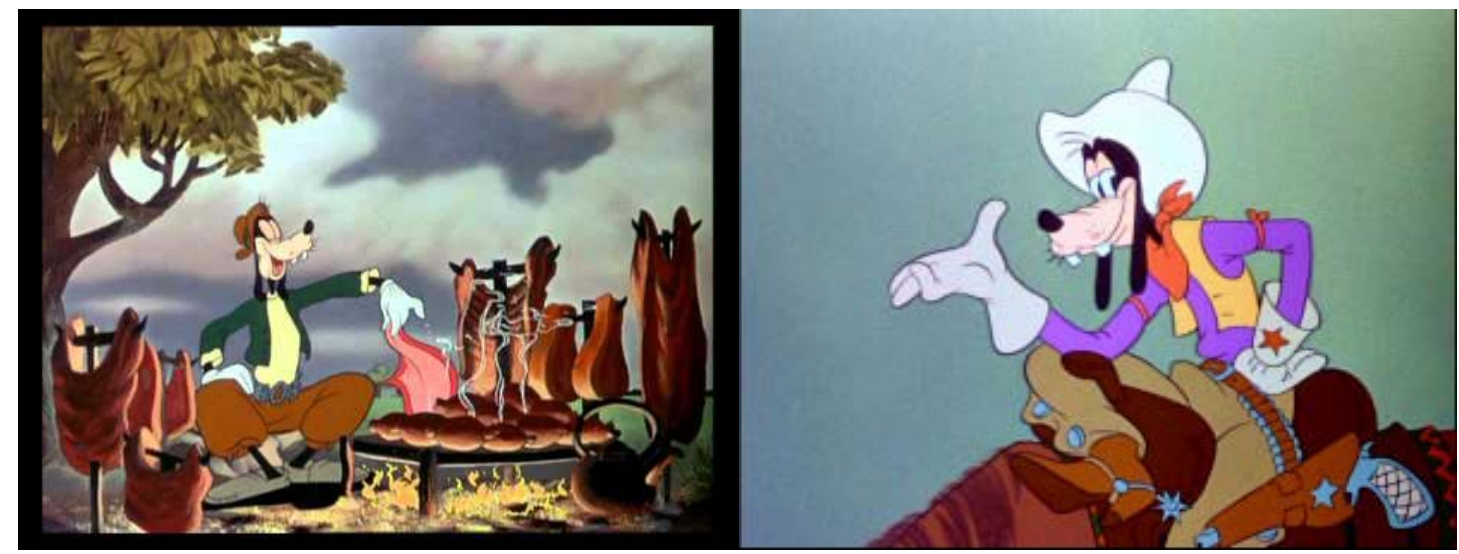

Fonte: Fotogramas capturados del cortometraje "El gaucho Goofy"

La figura del gaucho Goofy parece parodiar la del indio Patoruzú al reponer su imagen telúrica a partir de una versión caricaturizada. En efecto, el Patoruzú aparecía en las tiras de La 
Razón desde 1928 pero su consagración llegó cuando su creador, Dante Quinterno, visitó en 1933 los Estudios de Disney. El primer número de la revista salió a los quioscos en noviembre de 1936, agotando su edición de cien mil ejemplares en el primer día de venta. Los cursos de dibujo humorístico impartidos por Quinterno en las páginas de su revista, no son un hecho menor. El editor buscaba imprimir a otros dibujantes las lecciones inaugurales del oficio con el objetivo de estandarizar la producción y serializar el trazo: este método de dibujo, con tinte local, sigue el esquema de industrialización gráfica creado por Walt Disney.

Figura 8 - Elementos telúricos, idiosincrasia y nación

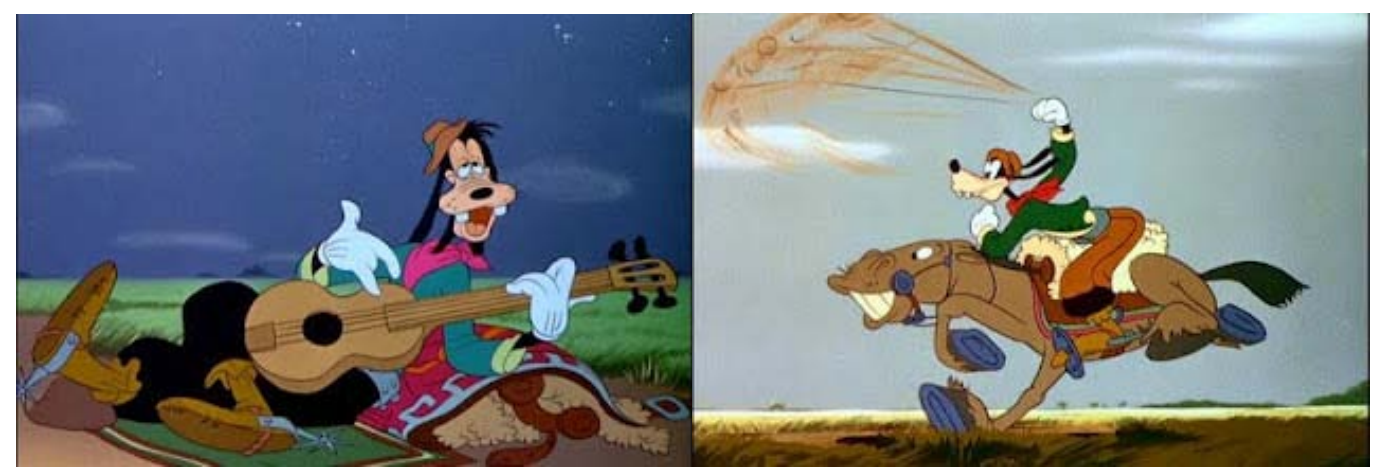

Fonte: Fotogramas capturados del cortometraje "El gaucho Goofy"

Pero no sólo el gaucho, aparece como elemento articulador del sentimiento nacional. El tango y el asado forman parte de la construcción de estereotipos marcadamente argentinos. Es evidente que si la misión tenía por objetivo integrar las diferencias a partir de la concepción del panamericanismo qué mejor que mostrar al propio Walt Disney y no a sus personajes disfrutando de un asado o bailando una chacarera. En el filme se cuelan los dibujos animados con los dibujantes trabajando "en vivo"; la continuidad establecida preanuncia una utopía no conflictiva, casi un fundido encadenado de realidad y fantasía.

Figura 9 - Disney bailando con el grupo de danza de Andrés Chazarreta, en la terraza del hotel. 


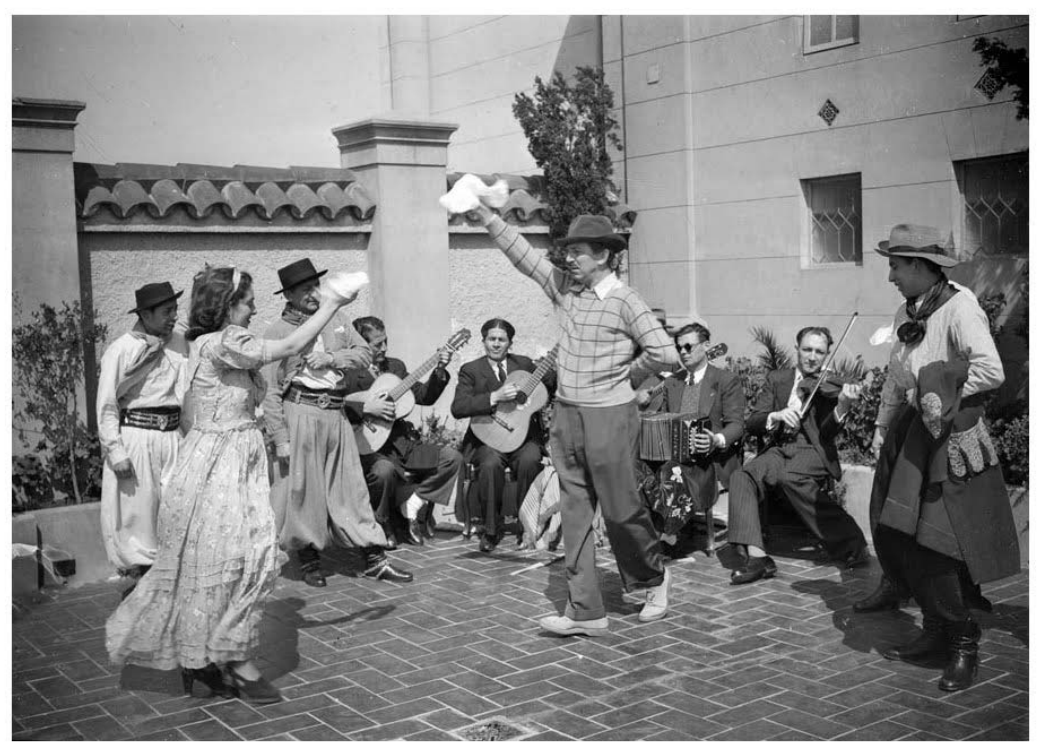

Fonte: Imagen obtenida del filme Walt y el Grupo (2008)

Tras su gira por Buenos Aires, el equipo voló rumbo a Mendoza y el 29 de septiembre partieron hacia Santiago de Chile en donde permanecieron algunos pocos días. La operación fue la misma que en la Argentina. Esta vez, el grupo estableció su centro de operaciones en el Hotel Carrera de Santiago. Fernando Purcell (2010, p. 512) analiza la posición de la prensa de la siguiente manera:

Tal vez el hecho de que Estados Unidos no hubiera entrado formalmente al conflicto al momento de la visita de Walt Disney pueda explicar las reacciones poco suspicaces de la prensa chilena hacia su presencia. La revista Ecran indicaba en 1941, por ejemplo, que a pesar de que estallasen los "más terribles conflictos bélicos", Mickey Mouse siempre conservaría su "sonrisa contagiosa" y el Pato Donald su "atrevido optimismo", porque "como nada les importa a ellos. Han sido creados para entretenernos". En definitiva, lo que Disney buscaba con su viaje a América Latina era, por tanto, un "enriquecimiento intelectual”. El Diario Ilustrado destacó que la venida de Disney respondía a su necesidad de "empaparse en el ambiente sudamericano", para que pudiese "comprendernos más" antes de la creación de sus cartones." 
Sin embargo y siguiendo lo señalado por el autor, si bien originalmente se había pensando en incluir dos personajes chilenos (un avión llamado "Pedrito" y un pingüino bautizado "Pablo") sólo el primero mantendría su nacionalidad, porque el segundo, que apareció en el filme Tres Caballeros, se transformó en un personaje sin nombre "representativo" de la costa oeste sudamericana. (PURCELL, 2010, p. 516) La película fue estrenada en Chile en septiembre de 1942, generando reacciones de expectativa de parte de un público que aguardaba la exhibición del filme tras el paso recordado de Disney el año anterior. Sin embargo, y como señala Purcell, la representación del pueblo chileno se vio claramente deslucida frente al resalte de las geografías, valores y tradiciones de Argentina y Brasil.

La historia de Pedrito fue foco de atención de la crítica chilena. Lo que la animación muestra es la adversidad climática, el viento peligroso y huracanado, las lluvias temibles y el invencible Aconcagua, señala Purcell: "de la cuatro secciones de la película, la de Pedrito es la más débil. El personaje "chileno", a diferencia del brasileño José Carioca y de los consagrados Donald y Goofy, que visitan el lago Titicaca y Argentina, respectivamente, es el menos cómico y atractivo" (PURCELL, 2010, p. 518).

Figura 9 - Fotograma del episodio "Pedrito".

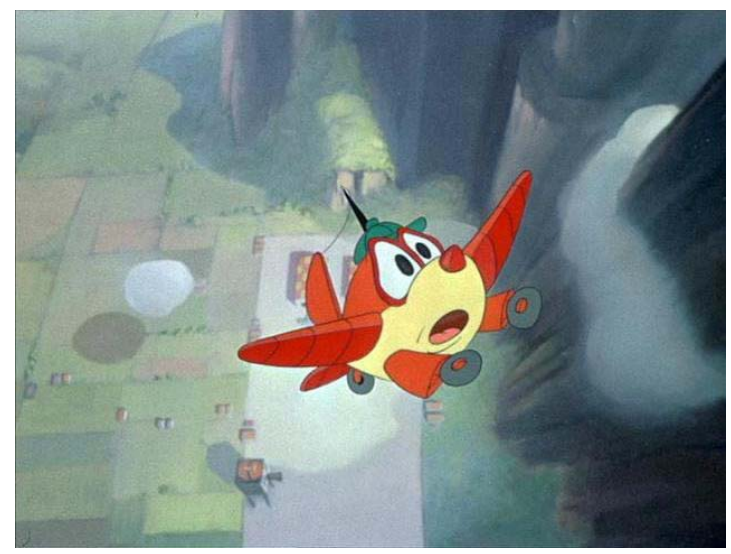

Fonte: Purcell, 2010. 
Este desencanto percibido por el público en general, da cuenta del rumbo promisorio que había encarnado la empresa. El retrato de América Latina en una sucesión de estampas tradicionales, el resalte de arquetipos y costumbres había dado por resultado el trazado de un mapa multicolor: la fauna y flora de Brasil, la extensa y verde pampa Argentina, la Bolivia indígena y rica en costumbres y paisajes. Todo un folclore criollista y campesino que poco tenía de tercer mundo y afán modernizador. De regreso a Estados Unidos el equipo creativo de Disney se lanzó a la tarea de producir los filmes, incorporando los objetivos planificados antes del viaje. $\mathrm{Al}$ registro de los ambientes naturales, los encuentros culturales, las comidas y visitas guiadas se le sumaron los elementos propagandísticos.

Los cortometrajes fueron fusionados en dos grandes producciones. Contar la aventura como un cuaderno de bitácora también tuvo su rédito. Disney y su compañía sacó el máximo provecho posible del periplo por América Latina: no sólo registró, filmó y dirigió las animaciones, sino que publicó tiras cómicas narrando el viaje, se realizaron filmes documentales cuyo elenco estuvo conformado por la comitiva, se vendieron fotografías a revistas y periódicos y publicaron libros sobre la arriesgada empresa. Al fin y al cabo, la misión política y cultural, también era un buen negocio.

\section{Upa en Apuros}

En este sentido, Disney vendría a funcionar como un aliado y una "amenaza” al mismo tiempo. En otros términos, frente al indio Patoruzú (que no es el gaucho pero se presenta en tanto tal) estaba el héroe americano, el Pato Donald, un claro adversario en el horizonte de expectativas de éxito y reconocimiento. Estos personajes, con sus marcas identitarias, se presentan como seres torpes, bonachones, dueños de virtudes, desprovistos de intenciones políticas y sobre todo, sin doble moral.

Representantes de una "identidad nacional” proponen un ideal de vida desinteresado y acogen con entusiasmo las tradiciones y enseñanzas que les brindan la familia y las buenas costumbres. Atados a su tierra, nunca son extranjeros. El indio Patoruzú o el Gaucho Goofy en las Pampas se resisten al cambio de tradiciones: ellos más que ningún otro, "pisan fuerte en su propias tierras".

Figura 10 - Goofy: intentando “dominar el poncho” Figura 11 - El Indio Patoruzú. 


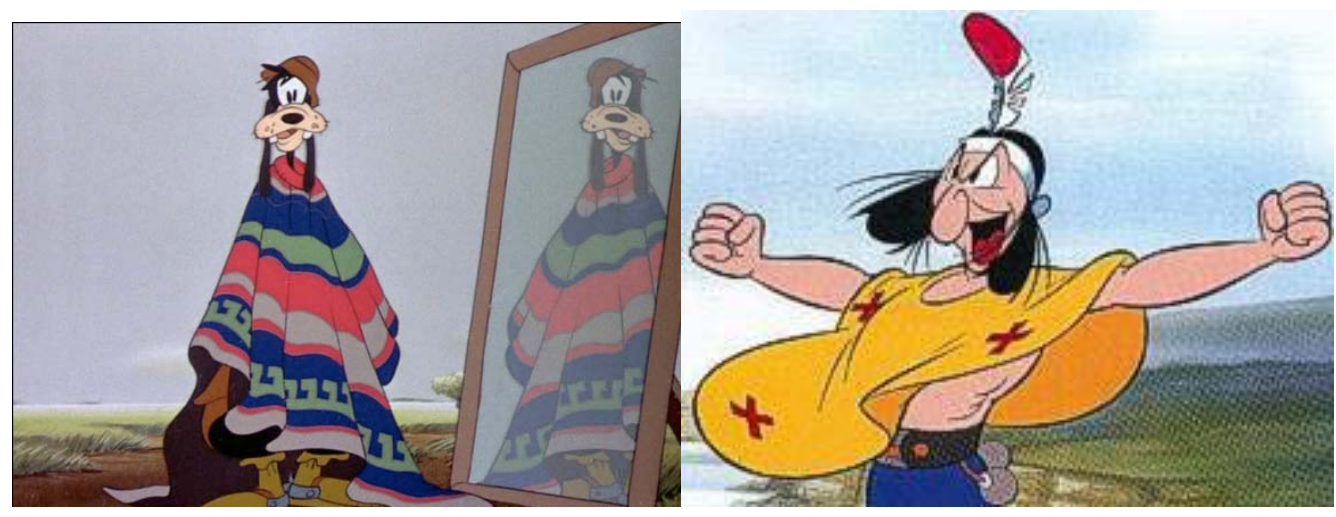

Fonte: Archivo personal de la autora

Por otro lado, tampoco hay dramas morales ni grandes pasiones. La psicología de los personajes de Quinterno, como las de los de Disney, sostiene una concepción del fracaso que es casi, un alivio. En verdad, la felicidad y el desengaño no existen en tanto tales: las peripecias se sobrepasan y la vida continúa sin demasiadas pretensiones o ambiciones de cambio. Al mismo tiempo, el indio Patoruzú nunca es “inocente” y su aparente candidez y torpeza esconde a duras penas la sospecha ideológica. Arquetipo del héroe argentino no puede ser sino, una falacia. Como señala Oscar Steimberg (1977) la ideología revela su impostura ya que las virtudes del "indio" Patoruzú son virtudes criollas, no indias:

Patoruzú tiene virtudes gauchas pero es un indio; los indios y los gauchos nunca fueron algo parecido a una unidad social. Por otra parte, es un gran terrateniente, pero además es un cacique indio del sur; y esta otra dualidad se da en un momento en que todavía estaban muy cerca, en el tiempo, las matanzas de indios de las que fueron responsables indirectos y aun directos, casualmente, terratenientes del sur. [...] En realidad, la identidad social de Patoruzú es tan intocable y tan inaprehensible como su dinero. Ni uno ni la otra pueden ser amenazados por la realidad objetiva; y aún más: ni uno ni otra pueden siquiera definirse con exactitud en sus características básicas. En este sentido, la situación social y económica de Patoruzú se parecería al ideal de un estanciero real, que además fuera un hombre de derecha, y que quisiera no sólo conservar intacto y libre de peligros su patrimonio, sino también intacta y no cuestionable su condición social, convirtiéndola en algo indefinible y evanescente" (STEIMBERG, 1977, p. 65-66) 
Ahora bien, menos conocida que la biografía de Disney rodeada de un anecdotario mítico que alimenta su figura legendaria, la historia de Dante Quinterno apenas es recordada por sus personajes más populares o para los conocedores, por su rol fundacional en el Primer Sindicato Argentino de distribución de historietas. Oscar Steimberg (1977) ya ha descripto las características esenciales del "universo Quinterno". Personajes con conductas paternalistas, xenófobos y clasistas. El ideario político privilegia los intereses del capital concentrado y es notable el apoyo a las dictaduras en distintas etapas de circulación de la historieta.

Este nacionalismo conservador y de derechas llevaría a que Quinterno no autorizara la utilización de la imagen de sus personajes para ilustrar los afiches de la Primera Bienal Internacional de la Historieta, realizada en el Instituto Di Tella (1968). ${ }^{11}$ Pero este horizonte ideológico netamente tradicionalista, no entraría en contradicción con las certidumbres modernistas del constitucionalismo liberal. Se trata de una cristalización ideológica que impugna la democratización de la vida política por un lado pero, por el otro, usufructúa los réditos del progreso, la industrialización y el proyecto burgués.

Dante Quinterno, en tanto empresario y editor de revistas de historietas vislumbra hacia principios de la década del cuarenta un proceso de transformación en la industria del entretenimiento. Como empresario hábil y exitoso, pero también, como terrateniente millonario, advierte que el mercado de revistas de historietas (del cual es uno de los principales referentes) necesita expandir sus fronteras hacia otras zonas de la industria. De allí que en un momento de apogeo de sus revistas decide redoblar su apuesta y diversificar su producción.

Es así como se lanza a producir el primer cortometraje a color en la Argentina: Upa en Apuros". La producción reveló una empresa faraónica, altos costos, pérdidas económicas y un estreno pospuesto desde el 21 de abril hasta el 20 de noviembre de 1942 en el cine Ambassador durante el estreno de "La Guerra Gaucha". El corto de tiene una duración de doce minutos fue producido por el Sindicato Dante Quinterno, con Tito Davison como director, Tulio Lovato como jefe de producción, Oscar Blotta como animador principal, decorados del pintor alemán Gustavo Goldschmidt y story-boards del propio Quinterno. Como partitura se utilizó el fondo musical Melle Veersma.

Figura 12 - Afiches promocionales del cortometraje Upa en Apuros

\footnotetext{
${ }^{11}$ He trabajado en detalle este evento en mi tesis doctoral: Oficio, arte y mercado. Historia de la historieta argentina. 19681984. (Facultad de Ciencias Sociales, UBA, 2010)
} 

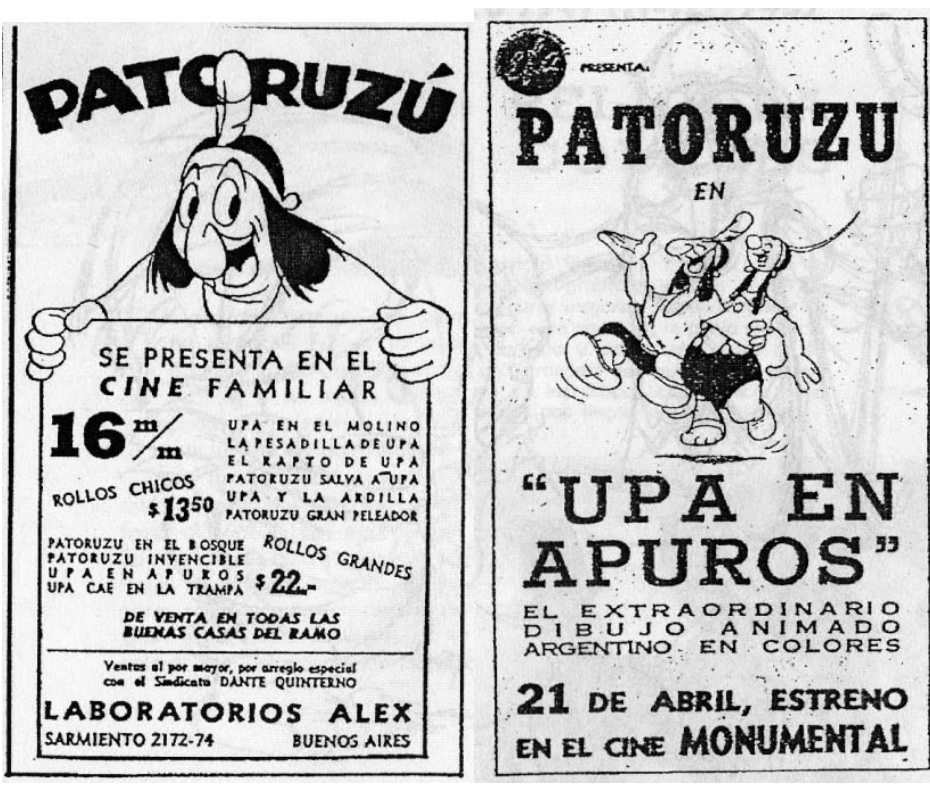

Fonte: La Bañadera del Cómic, 2001.

Ya no se trata de transitar la llamada edad de oro de la historieta nacional con paso confiado y optimista. Quinterno se arriesga e incursiona en el cine como un representante singular de su tiempo, una mentalidad que encaja de lleno con las relaciones entre técnica e industria durante la segunda mitad del siglo veinte. Entonces, por un lado, hay que resaltar el carácter indudablemente pionero que asume su producción pero, por el otro, exponer que su sensibilidad forma parte de un escenario en el cual distintas prácticas vinculadas al ocio y la diversión se expresaron ampliamente.

Las decenas de películas de animación a color realizadas en el mundo parecen confirmar lo obvio: Quinterno podría ser un pionero pero difícilmente un inventor iluminado. En 1933, viaja a Estados Unidos para aprender de los grandes sindicatos distribuidos de historietas. Es así como en 1935, funda el Sindicato Dante Quinterno, a través del cual distribuyó su producción en Norteamérica. En 1936, Patoruzú gana una página semanal en Mundo Argentino, a todo color y es reeditado en numerosos diarios del interior del país. Con el correr de los años la línea editorial se diversifica y amplia y varios personajes obtiene su propia revista: Andanzas de Patoruzú (1956), Patoruzito (1945), Correrías de Patoruzito (1958) y Locuras de Isidoro (1968).

Completamente diversificado, el Sindicato licenció el personaje con fines publicitarios: muñecos, almanaques, jabones, juguetes, prendedores, rompecabezas, discos y un programa de diario. Sólo faltaba "entrar" al negocio del cine. Casi como sumar dos más dos. 


\section{Esos buenos salvajes}

Aunque la retórica de la buena vecindad opera como un principio de solidaridad americana contra el enemigo externo uno de sus elementos fundantes fue resaltar la identidad de cada nación y la autonomía de sus democracias republicanas. Esta discursividad llevaría a que se pongan sobre un primer plano los rasgos de la llamada "idiosincrasia cultural", prestando especial al clima de cada región, sus alimentos, vestimentas autóctonas y costumbres. Como señala Mónica Glik "a través de una dialéctica de inclusión (los americanos) y exclusión (los amigos del Eje), se decidía quién quedaría afuera, y quién adentro". (GLIK, 2009, p. 17)

En todo caso, el ideario que sobrevuela a cualquier diferencia es el modo de vida norteamericano. La acotada resignificación de esa ideología puede advertirse en las prácticas empresariales de un editor como Dante Quinterno. Que no es Disney, aunque le hubiese gustado serlo y que con lo que tenía a mano, como un buen inmigrante, hizo de la necesidad, virtud. Ideología y mercado se conjugaron para revelar un repertorio iconográfico y narrativo que dejó su huella en el imaginario de los profesionales del medio y en el público lector.

Posicionarse en la industria implicaba dejar de lado la evocación nostálgica y afirmar su carrera en el progreso. Su reacción nacionalista no iría a contramano de ello: cuidar la herencia y defender la tierra implicaba también enfrentar el gringo con "pasión criolla". De allí que inventó su propio mito: un indio terrateniente, espíritu de la raza y auténtico argentino. Frente a él, también un imposible. En Goofy en las Pampas, cuando el personaje intenta comprender las costumbres del gaucho, fracasa en todo intento. No podía ser de otro modo, Quinterno y Disney siempre dejan en claro que los mundos aunque se parezcan, no deben mezclarse.

En este sentido, parece insuficiente ver la relación con el progreso solamente desde sus efectos. Podría plantearse que la historia de los proyectos nacionales (aún la de aquellos inacabados) siempre está en advenimiento y que más allá de los flujos desiguales y los rumbos impredecibles, la modernidad como ideal móvil y en su plenitud de contradicciones no siempre perjudica al "más débil". Así, el apresuramiento para poner a punto la industria nacional y competir en el mercado internacional es más que una respuesta imitativa.

Para finalizar: las relaciones dinámicas que la actividad historietística estableció con la industria cinematográfica y más adelante con la televisiva encuentra su correlación con momentos álgidos de estos sectores. No podría en estas páginas detenerme en este aspecto, pero hay que destacar que la incursión de Dante Quinterno en el cine no se trata de un fenómeno aislado ni es resultado solamente de la ambición o el azar, sino que forma parte de un conjunto de 
estrategias de imbricación entre las casas editoriales y otros medios de comunicación. Obviamente, estudiar de manera complementaria la historia de la historieta y la historia de los medios es un proyecto más amplio del que sólo presenté aquí un caso acotado y restringido.

\section{Referencias}

BURKE, Meter. Formas de historia cultural. Madrid: Alianza, 2000.

CERTEAU, Michael de. La invención de lo cotidiano. México: Universidad Iberoamericana, 1999.

COLECTIVO LA BAÑADERA DEL CÓMIC (Hernán Ostuni, Fernando García, Andrés Ferreiro, Mario Formosa y Rodríguez Van Rousselt). Patoruzú. Vera historia no oficial del grande y famoso Tehuelche. La Bañadera del Comic, Buenos Aires, 2001

GARCÍA CANCLINI, Néstor. Negociación de la identidad en las clases populares. Consumidores y ciudadanos. México: Grijalbo, 1995.

GLIK, Mónica Sol. Los vecinos de Roosevelt: Argentina, Brasil y el panamericanismo (1931-1945) In: SEMINARIO DE INVESTIGACIÓN DEL DOCTORADO EN HISTORIA CONTEMPORÁNEA, 2009. UCM. Disponible en: $<$ http://www.ucm.es/info/hcontemp/Sol_Glik_29_1_2009.pdf $>$. Acceso en: 10 abr. 2010.

GOOFY: gaucho argentino. Disponible en:<http://www.youtube.com/watch?feature= endscreen\&NR=1\&v=ZvhiQD0kN7Q>. Aceso en: $10 \mathrm{abr}$. 2012.

ORTIZ, Renato. Mundializaçao e cultura. São Paulo: Brasiliense, 1994.

PURCELL, Fernando.Cine, propaganda y el mundo de Disney en Chile durante la segunda guerra mundial. HISTORIA, Santiago de Chile, v. 2, n. 43, p. 487-522, Jul./Dic. 2010.

STEIMBERG, Oscar. 1936-1937 en la vida de un superhéroe de las pampas. En:_ _ _ _ . Leyendo historietas. Estilos y sentidos en un "arte menor". Buenos Aires: Nueva Visión, 1977.

UPA en Apuros. Cortometraje de Dante Quinterno. Disponible en: $<$ watch?v=T7BO5U-Dn8g Aceso en: 10 abr. 2012.

VAZQUEZ, Laura. El oficio de las viñetas: la industria de la historieta argentina. Buenos Aires: Paidós, 2010.

WALT Disney no Brasil. Veja, 16 ago. 2011. Disponible en:<http://veja.abril.com.br/ blog/sobreimagens/classicos/walt-disney-no-brasil/>. Aceso en: 9 abr. 2012. 
WALT Y EL GRUPO. 2008. Disponible en:<http://www.waltandelgrupo.com/>. Aceso en: 6 mar. 2012.

Recebido em 30/02/2012

Aprovado em 30/05/2012 